\title{
Gestão de estoques de uma empresa do ramo de entretenimento: proposta de uma curva $\mathrm{ABC}$
}

\section{Stock management of an entertainment branch company: proposal for an ABC curve}

\author{
Recebido: 06/04/2020 - Aprovado: 18/09/2021 - Publicado: 1/9/2021 \\ Processo de Avaliação: Double Blind Review
}

\author{
Pamela Amado Tristão \\ pamela.tristao@furg.br \\ Universidade Federal do Rio Grande \\ http://orcid.org/0000-0002-8408-6942 \\ Matheus Henrique de Siqueira Quoss \\ matheus.t.t_siqueira@hotmail.com \\ Universidade Franciscana (UFN) \\ http://orcid.org/0000-0002-9474-6967
}

\section{RESUMO}

O presente estudo analisou o estoque da empresa Fest Entretenimentos por meio do cadastramento dos produtos utilizados para a prestação de serviços, de maneira a verificar seu consumo por meio da curva ABC. Para esse alcance foi realizado o levantamento dos itens utilizados para a prestação dos serviços da empresa no período de fevereiro a junho de 2018. O montante investido em estoque ao longo do período foi de $\mathrm{R} \$ 34.743,29$. Desses, os itens da classe A, que representam $80 \%$ do valor investido em estoques, totalizando 11 itens. Os produtos de classificação B são compostos por vinte e cinco itens de importância intermediaria na organização, totalizando $15 \%$ da demanda em valor monetário; os itens da classe $\mathrm{C}$, por possuírem um baixo valor agregado, representam grande quantidade de produtos, representando $5 \%$ do valor de demanda monetária.

Palavras-chave: gestão de estoques, curva abc, empresa de entretenimento.

\section{ABSTRACT}

This study analyzed the stock of Fest Entertainment through the registration of products used to provide services to verify their consumption through the ABC curve. To achieve 
the objective, a survey of the items used in the company's services from February to June 2018 has been conducted. The amount invested in inventory over the period has been $R \$$ 34,743.29. In this value, class A items represent $80 \%$ of the amount invested in inventories, totaling 11 items. Products classified as B are composed of twenty-five items of intermediate importance in the organization, totalizing $15 \%$ of the demand in monetary value; Class $C$ items, due to their low value, represent a large quantity of products, representing $5 \%$ of the value of monetary demand.

Keywords: stock management, abc curve, entertainment branch company.

\section{INTRODUÇÃO}

A dinâmica empresarial exige, cada vez mais, que as empresas administrem seus recursos de maneira a otimizar o investimento, bem como atender à demanda dos clientes. Nesse escopo, a gestão de estoques constitui-se como ferramenta fundamental, uma vez que, para Dias (2010), sua função consiste na habilidade ou nas ações tomadas pela empresa no sentido de otimizar o manejo dos materiais e reduzir a necessidade de investimento de capital em altos estoques. A administração de estoques pretende, de maneira geral, assegurar a quantidade adequada de materiais, de maneira que não haja excesso, nem ruptura no processo produtivo de determinado bem ou prestação de serviços (RODRIGUES et al., 2018; VAGO et al., 2013).

Nesse sentindo, o estabelecimento dos níveis adequados de estoques é considerado uma tarefa complexa, em função, para Rodrigues et al. (2018), de fatores econômicos, políticos, de planejamento, riscos logísticos, questões de sustentabilidade, entre outros. A escolha de ferramentas eficientes para auxiliar os gestores de almoxarifado na administração dos materiais se torna, portanto, fundamental para que os problemas que as empresas vêm enfrentando nesse setor sejam reduzidos (SLACK et al., 2007); haja vista que tais ferramentas são suportes às organizações (WANKEE, 2006).

Entre as ferramentas de maior utilização nas empresas é possível citar a curva $\mathrm{ABC}$, cuja implementação permite identificar os itens que necessitam maior atenção (BALLOU, 2006). Segundo Faria e Costa (2005), sua utilização no ambiente empresarial contemporâneo, como uma das ferramentas para análise de estoques mais aplicadas, deve-se à sua simplicidade, praticidade e eficiência, que se adequa a diferentes tipos de

REMIPE- Revista de Micro e Pequenas Empresas e Empreendedorismo da Fatec Osasco V. 7 N² set.2021 a fev. 2022. 
organizações entre vários segmentos, pois ela busca compreender a relação entre o investimento aplicado, o consumo do estoque e a quantidade de itens que o constituem.

A empresa em que a presente pesquisa foi aplicada, Fest Entretenimentos ${ }^{1}$, constitui-se como uma pequena empresa prestadora de serviços do ramo do entretenimento, oferecendo produtos e serviços de coquetelaria, animação de festas, elaboração de coreografias, serviços de fotografia e de filmagem. Especificamente a prestação dos serviços de coquetelaria demanda uma grande variedade de produtos estocados, os quais vão desde insumos para a preparação das bebidas a materiais de uso como utensílios. No entanto, não existe controle suficiente sobre a demanda e a real necessidade de estocagem dos produtos e, especificamente, os mais importantes para a manutenção dos serviços prestados.

Diante dos posicionamentos apresentados, o presente estudo tem como objetivo analisar o estoque da empresa Fest Entretenimentos por meio do cadastramento dos produtos utilizados para a prestação de serviços de maneira a verificar seu consumo com a aplicação da curva $\mathrm{ABC}$.

A motivação para a presente pesquisa está relacionada à sua aplicabilidade e à importância da área estudada para as organizações, em especial as de pequeno porte, nas quais, de acordo com Gianesi e Biazzi (2011), não tem sido abordada de maneira formal o suficiente, acarretando o manejo inadequado dos materiais estocados. A dificuldade de controlar o fluxo de materiais de maneira adequada, para Lourenço e Castilho (2006), pode estar relacionada à grande diversidade de materiais e, muitas vezes, informações insuficientes nos setores responsáveis.

Nesse cenário, o estudo e a aplicação de ferramentas que auxiliem a gestão adequada de estoques podem ser entendidos como uma estratégia de gestão, a qual permite a identificação de materiais de maior importância no estoque, tonando possível, para Araújo et al. (2018), que as empresas consigam atender à demanda requerida sem comprometer recursos desnecessariamente, tornando-as mais competitivas perante seus concorrentes. Além dos aspectos que envolvem o investimento de recursos financeiros, cabe também mencionar a redução de falhas nos processos internos como recebimento e conferência de mercadorias na empresa, atribuições do comprador, entre outras situações (RONCHI, 2014).

\footnotetext{
${ }^{1}$ Com o objetivo de preservar a identidade da empresa, foi alterado o seu nome, sendo utilizado "Fest Entretenimento".
}

REMIPE- Revista de Micro e Pequenas Empresas e Empreendedorismo da Fatec Osasco V. 7 N² set.- 
Devido aos benefícios obtidos por meio da gestão adequada de estoques com auxílio da curva $\mathrm{ABC}$, diversos estudos tiveram como foco apresentar sua aplicação. Nack e Bonfadini (2013) com foco de pesquisa em uma grande empresa atuante no segmento eletroeletrônico; Oliveira et al. (2015) nos estoques de uma metalúrgica do setor de autopeças; Vago et al. (2013) na gestão do almoxarifado de um Centro de Pesquisa Federal; Bezerra e Araújo (2018), por sua vez, analisaram o setor automobilística de revenda de autopeças. A presente pesquisa inova, dessa forma, por meio da escolha do segmento a ser estudado, pouco explorado até então, com a prestação de serviços de entretenimento de uma empresa de pequeno porte.

Inova-se por abordar a gestão de estoques de uma empresa desse segmento relevante que, segundo pesquisa realizada pela Folha de São Paulo (KNAPP, 2016), tem uma propensão de crescimento de $6,4 \%$ no Brasil até 2021, atingindo um faturamento anual de aproximadamente $\mathrm{R} \$ 153,9$ bilhões.

Após essa breve introdução do tema abordado, o segundo capítulo apresenta o referencial teórico que embasa a pesquisa. No capítulo três são delineados os procedimentos metodológicos como a classificação da pesquisa, a coleta de dados etc. Os resultados são apresentados e discutidos ao longo do quarto capítulo e, por fim, são apresentadas as considerações finais no capítulo cinco.

\section{A ADMINISTRAÇÃO DE MATERIAIS E CONTROLE DE ESTOQUES}

Os estoques, de acordo com Rodrigues et al. (2018), existem com a finalidade de atender às demandas futuras, as quais podem oscilar em determinados períodos, tonandose, de acordo com algumas características do setor e das empresas, imprevisíveis. De maneira complementar, para Corrêa e Corrêa (2008), os estoques têm como função regular as diferentes taxas de suprimento e consumo de determinado insumo. A estocagem, portanto, objetiva a armazenagem temporária e distribuição de materiais, de maneira que não faltem materiais ao longo do processo produtivo, evitando a alta imobilização de recursos financeiros (POZO, 2010).

Gerir os estoques torna-se, dessa forma, um fator primordial nas empresas, exigindo nível adequado de demanda, eficiência nas atividades de produção e distribuição, de maneira que os recursos investidos em inventário sejam reduzidos. A

REMIPE- Revista de Micro e Pequenas Empresas e Empreendedorismo da Fatec Osasco V. 7 N $^{\circ} 2$ set.2021 a fev. 2022. 
gestão de estoques em suma, é o planejamento e o controle de mercadorias para uma rápida dispersão, desde a sua entrada (input) até a sua saída (output) (DIAS, 2010).

Apesar de sua simplicidade, para que este processo ocorra de forma exímia, é necessário que o gerente de estoques esteja atento a três situações: a) Crescimento ou redução da rotatividade de mercadorias; b) Aumento ou diminuição da obsolescência e dos custos dos produtos estocados e; c) Variação das vendas em virtude da estocagem de produtos realmente necessários. Assim, um dos propósitos fundamentais da gestão de estoques é proporcionar disposição de produtos para quando ocorrer eventos não planejados, que podem afetar toda a cadeia como, por exemplo, atrasos no abastecimento, greves e desastres naturais (BALLOU, 2006).

Apesar da sua relevância para as organizações, a utilização de metodologias adequadas para a apuração dos dados para a manutenção de estoques que possibilitem melhoramento nas análises, no que tange a conflitos entre os níveis de serviço, eficiência das operações e níveis de estoque, ainda é considerada deficitária em uma parcela considerável de empresas (BOWERSOX e CLOSS, 2007). Neste escopo, Slack et al. (2007) expõem ser necessária a implantação de políticas que busquem melhorar a gestão dos estoques, levando em consideração a sua importância e os impactos que podem causar com custos organizacionais.

Mediante o importante papel dos estoques nas organizações, torna-se necessária a utilização de ferramentas que auxiliem sua gestão, de modo a otimizar os recursos de capital investidos, de modo que as empresas continuem seu processo produtivo de maneira ininterrupta. Dentre o ferramental existente, é possível citar ferramentas como a utilização do cálculo de giro de estoque; a realização do inventário físico de maneira periódica ou permanente; a acurácia de estoques; o cálculo dos pontos de reposição ou de pedido dos principais produtos e itens estocados pela empresa; bem como a cobertura de estoque e; a análise de curva abc.

$\mathrm{O}$ giro de estoque, especificamente, indica quantas vezes, em determinado período, o estoque renovou-se, utilizando como base de cálculo, o valor consumido no período dividido pelo valor do estoque médio no período (MARTINS e LAUGENI, 2006). Para Dias (2010), o inventário físico tem por função fazer a contagem física dos itens que constam no estoque, assim, pode-se verificar se há divergências entre o inventário físico e o que realmente consta nos registros de controle de estoque. Martins e Laugeni (2006) complementam dizendo que acurácia de estoques utiliza como base de 
cálculo o valor dos itens corretos divididos pelo valor total dos itens e funciona como um complemento para o inventário físico. Ponto de reposição ou de pedido representa a revisão contínua, ou seja, o momento ideal de se realizar um pedido para repor o estoque, baseado na sua demanda, através do lead time e no estoque de segurança, assim, é estabelecido um nível mínimo de estoque que, quando atingido, dispara um pedido e, para que isso ocorra, é utilizada uma fórmula que calcula a demanda média diária multiplicando pelo tempo de ressuprimento e somando ao estoque de segurança em unidades.

Além destas ferramentas apresentadas acima, existe uma muito utilizada na prática empresarial, a curva $\mathrm{ABC}$, que é apresentada no tópico a seguir.

A curva $\mathrm{ABC}$, ferramenta para controle de estoque, consiste na ideia de verificar e ordenar, em graus de importância, os materiais ou insumos que devem receber maior atenção a partir de sua classificação para a empresa; devendo, então, receber maior atenção e ser tratados com certa prioridade, permitindo ao administrador maior planejamento e reposição de materiais de forma assertiva (RODRIGUES et al., 2018),

Basicamente, a análise $\mathrm{ABC}$ se baseia na separação de todos os bens de um estoque de maneira que eles sejam divididos em três grupos de acordo com seu valor de demanda anual. Esse valor anual é determinado pela multiplicação do preço ou custo unitário de cada item pelo seu consumo ou sua demanda anual (DIAS, 2010).

Após os itens serem classificados em A, B ou C, é importante que se aplique os diferentes graus de controles, adequando-os em suas classes de produtos e determinando um padrão de controle para os produtos $\mathrm{X}$ e, ao mesmo tempo, insuficiente para os produtos Y. É importante verificar as diferenças que existem no estoque para escolher as melhores formas de controle levando em consideração a necessidade de cada produto existente. Também, é possível estender a análise levando em consideração outras variáveis como: a tendência, a perecibilidade, o espaço de armazenamento disponível, descontos oferecidos, entre outros (MARTINS e LAUGENI, 2006).

Segundo Santos e Grander (2012), para construir a curva ABC é necessário seguir um processo que exige algumas informações como: o código do material ou item, a demanda em unidade de cada item durante o período estudado. Na etapa seguinte, é calculada a demanda em relação aos bens enviados e; na sequência ocorre a ordenação decrescente dos produtos e a elaboração da curva ABC. A Figura 1 apresenta a forma como são posicionados os itens em seus respectivos grupos.

REMIPE- Revista de Micro e Pequenas Empresas e Empreendedorismo da Fatec Osasco V. 7 N $^{\circ} 2$ set.2021 a fev. 2022. 
Figura 1 - Curva ABC

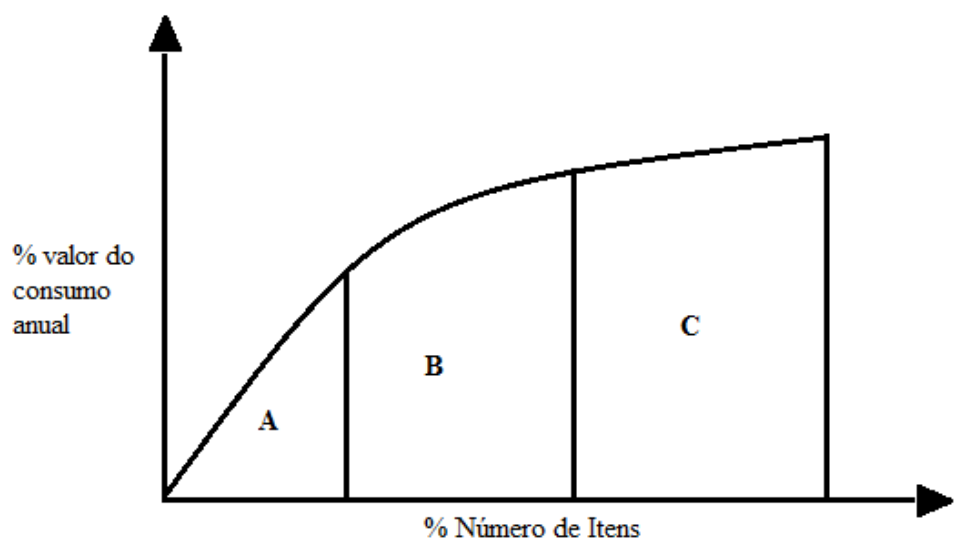

Fonte: Adaptado de Santos e Grander (2012).

De acordo com Ballou (1993), Martins e Laugeni (2006), a classificação ABC obedece uma ordenação de itens que são consumidos através da função de um valor financeiro, e os classifica como: a) Classe A: constituída por poucos itens (até $10 \%$ ou $20 \%$ dos itens), o valor de consumo acumulado é alto (acima de $50 \%$ até $80 \%$ em geral); b) Classe B: formada por um número médio de itens (20\% a $30 \%$ em geral), apresenta um valor de consumo acumulado ao redor de $20 \%$ a $30 \%$, e; c) Classe C: constituída por um grande número de itens (acima de 50\%), o valor de consumo acumulado é baixo entre $5 \%$ e $10 \%$.

Com base na classificação apresentada, essa ferramenta torna-se amplamente utilizada para planejamento, controle e gerenciamento dos estoques, em que os materiais devem ser agrupados e classificados conforme seu giro e saída do estoque. O princípio de análise da curva $\mathrm{ABC}$ pode, igualmente, ser aplicado em diferentes situações empresariais, permitindo a identificação dos itens que merecem maior atenção.

\section{METODOLOGIA}

O presente capítulo evidencia os procedimentos metodológicos adotados para o alcance do objetivo do estudo, evidenciando a classificação da metodologia utilizada no que tange à sua abordagem, aos seus objetivos e procedimentos. São ainda, apresentados a coleta e tratamento dos dados da pesquisa.

REMIPE- Revista de Micro e Pequenas Empresas e Empreendedorismo da Fatec Osasco V. 7 N² set.2021 a fev. 2022. 
Quanto à abordagem, a pesquisa é classificada como quantitativa, a qual teve como propósito coletar dados sobre as movimentações de materiais no almoxarifado da empresa e transformar informações em número para análise. Para Hair (2006), pesquisas de abordagem quantitativa permitem a análise em termos numéricos.

Em relação aos objetivos, a presente pesquisa classifica-se como um estudo descritivo, uma vez que efetuou a descrição da análise da curva $\mathrm{ABC}$ da empresa pesquisada. Segundo Gressler (2004), a pesquisa descritiva é usada para descrever fenômenos e situações existentes, identificar problemas e justificar condições, comparar e avaliar o que os outros estão desenvolvendo em situações e problemas similares, visando a aclarar situações para futuros planos e decisões

Quanto aos procedimentos, foi realizado um estudo de caso único, permitindo, conforme YIN (2005), a possibilidade de aprofundamento na compreensão de um determinado fenômeno, tornando possível a produção de análises detalhadas e a formulação de hipóteses para pesquisas futuras, possibilitando interpretações alternativas. A técnica de estudo de caso, nesta investigação, apresentou-se adequada pelo fato de permitir a explicação das especificidades em relação às dinâmicas e processos que ocorrem na empresa pesquisada.

Os dados sobre a Fest Entretenimento, prestadora de serviços do ramo do entretenimento, foram coletados por meio de pesquisa nos registros e controles de compras e itens utilizados para a prestação de serviços da empresa ao longo de um período de cinco meses, de fevereiro a junho de 2018. Ao tratar os dados coletados, por meio do software Microsoft Excel, foi possível identificar a quantidade de produtos, os custos unitários e os custos totais. A elaboração da curva $\mathrm{ABC}$ foi realizada por meio de uma amostragem dos 64 itens mais consumidos ao longo do período analisado, resultando em um investimento total de $\mathrm{R} \$ 34.743,29$. Cabe, no entanto, ressaltar que, no presente estudo, não foram contabilizados os produtos perecíveis (frutas, gelo) que, embora façam parte da produção das bebidas e drinks, não ficam armazenados no estoque, mas são comprados momentos antes da sua utilização.

A classificação $\mathrm{ABC}$ dos produtos mais consumidos pela empresa foi embasada no modelo utilizado por Ballou (1993) e Martins e Laugeni (2006). Para tanto, os produtos que demandam maior investimento da empresa estão presentes na classificação A, sendo estes responsáveis por $80 \%$ da demanda em valor monetário ou constituída por poucos itens (10\% a $20 \%$ dos itens). Já os produtos da classe B são responsáveis por $15 \%$ do 
valor monetário investido ou formada por um número médio de itens $(20 \%$ a $30 \%$ em geral) e, por fim, os produtos da classe C são representam 5\% do valor monetário investido ou, constituída por muitos itens (acima de 50\%).

\section{APRESENTAÇÃO E DISCUSSÃO DOS RESULTADOS}

A presente seção se destina a apresentar e discutir os resultados do presente estudo. Para tanto, inicialmente é apresentada uma breve descrição sobre a empresa para, posteriormente, ser apresentada a aplicação da curva $\mathrm{ABC}$ com base no seu estoque ao longo do período analisado.

\subsection{A Empresa}

A Fest Entretenimento, empresa escolhida para a realização da presente pesquisa, atua no segmento de prestação de serviços, mais especificamente de entretenimento, com aproximadamente dez anos de mercado. Os serviços prestados incluem produtos e serviços de coquetelaria (segmento abordado no presente estudo), animação de festas, elaboração de coreografias e ainda, serviços de fotografia e filmagem para eventos em geral.

A equipe de colaboradores é reduzida, restringindo-se aos dois sócios e três profissionais, sendo um da área de marketing e comunicação, um responsável pela compra de insumos e o controle desses materiais no estoque e ainda, um instrutor de dança. Os demais profissionais que trabalham para a empresa são autônomos e, requisitados mediante a demanda de festas e eventos nas cidades em que atuam. Ao longo do período de existência na empresa, a demanda por esses profissionais aumentou de maneira considerável, tendo, atualmente, uma equipe constituída por aproximadamente quarenta profissionais autônomos.

Especificamente a gestão dos estoques na empresa é feita de maneira informal, por meio da identificação e contagem semanal dos itens utilizados para a prestação do serviço analisado, no entanto, cabe ressaltar que ainda não são utilizadas ferramentas que possibilitem a otimização dos recursos investidos no estoque, tornando, dessa forma, a aplicação da curva $\mathrm{ABC}$ de grande importância para a maximização da empresa.

REMIPE- Revista de Micro e Pequenas Empresas e Empreendedorismo da Fatec Osasco V. 7 N $^{\circ} 2$ set.2021 a fev. 2022. 


\subsection{A proposta de curva abc}

A Fest Entretenimento conta com um estoque de mais de cem itens, incluindo produtos líquidos alcóolicos (vodcas, runs, tequilas, whisky etc.), produtos cremosos (leite condensado, creme de leite etc.), produtos líquidos não alcóolicos (sucos, xaropes etc.), produtos para elaboração de coquetéis (coqueteleira, medidores, pegadores de gelo, biqueiras etc.) e produtos de bar (placas de bar, estruturas, cubas de frutas, grades etc.). O estoque da empresa apresenta caráter de sazonalidade, com um aumento de aproximadamente $70 \%$ nos períodos de dezembro/março e julho/agosto devido a formaturas e casamentos. Logo é perceptível a necessidade de uma ferramenta que viabilize a eficiência das atividades de gerenciamento de estoque da empresa. Partindo desta premissa, o presente estudo se propôs a aplicar a ferramenta curva $\mathrm{ABC}$ com a finalidade de reduzir custos e otimizar os processos de gestão estoque.

Para realizar essa classificação foram levados em consideração o valor total do custo médio que cada item possui em estoque e a sua importância para o estoque. Com esses dados, foi possível verificar o percentual que cada item representa no valor total do custo médio.

A classificação do estoque com relação aos produtos existentes ocorreu da seguinte forma: $17,19 \%$ do percentual acumulado tem classificação A; $32,81 \%$ dos produtos são classificados como B e 50\% dos itens são definidos como C. A apresentação da classificação se inicia por meio da Tabela 01, a qual apresenta os itens classificados como A:

Tabela 01 - Itens da classe A da empresa

\begin{tabular}{|c|c|c|c|c|c|c|}
\hline Produto & Quantidade & $\begin{array}{c}\text { Custo } \\
\text { Unitário } \\
(\mathbf{R} \$) \\
\end{array}$ & $\begin{array}{c}\text { Custo Total } \\
(\mathbf{R} \$)\end{array}$ & $\begin{array}{c}\text { Percentual } \\
(\%)\end{array}$ & $\begin{array}{c}\text { Percentual } \\
\text { Acumulado } \\
(\%)\end{array}$ & $\begin{array}{c}\text { Classificação } \\
\text { ABC }\end{array}$ \\
\hline Bares & 5 & $3.000,00$ & $15.000,00$ & 43,17 & 43,17 & $\mathrm{~A}$ \\
\hline Copos transparentes & 7000 & 0,47 & $3.290,00$ & 9,47 & 52,64 & A \\
\hline Vodka & 70 & 29,90 & $2.093,00$ & 6,02 & 58,67 & A \\
\hline Cuba de frutas grande & 13 & 120,00 & $1.560,00$ & 4,49 & 63,16 & A \\
\hline Canudos & 10000 & 0,15 & $1.500,00$ & 4,32 & 67,47 & A \\
\hline Cuba de frutas média & 13 & 100,00 & $1.300,00$ & 3,74 & 71,22 & A \\
\hline Tapete grande & 14 & 70,90 & 992,60 & 2,86 & 74,07 & A \\
\hline Rum & 24 & 32,79 & 786,96 & 2,27 & 76,34 & A \\
\hline Coqueteleira & 26 & 25,50 & 663,00 & 1,91 & 78,25 & A \\
\hline Espumante & 12 & 27,00 & 324,00 & 0,93 & 79,18 & A \\
\hline Macerador & 14 & 23,00 & 322,00 & 0,93 & 80,11 & A \\
\hline
\end{tabular}

Fonte: Elaborado pelos autores. 
Na Tabela 01, verifica-se que 11 itens são classificados como os mais consumidos no período, identificados como A na curva, os quais referem-se a 17,19\% do total de itens do estoque e investimento de $\mathrm{R} \$ 27.831,56$ ao longo do período analisado. Dentre esses itens, é possível destacar algumas bebidas alcóolicas como vodka, rum e espumante, o que decorre do fato de esses insumos servirem de base parte considerável para bebidas do cardápio da empresa. Além destes, itens como copos e canudos também compõem o estoque que a empresa deve dar maior atenção.

Os itens classificados na classe A, para Dias (2010), devem ser tratados com atenção especial, haja visto que há necessidade de reduzir ao máximo o número de itens sem estoque nessa classe, considerada a mais importante. Além disso, os itens classificados nesta classe, conforme exposto pela Tabela 1, tal como Ronchi (2014) e Bezerra e Araújo (2018), representam os itens de maior valor de aquisição.

Na tabela 2, é possível identificar os itens classificados como B.

Tabela 02 - Itens da classe B da empresa

\begin{tabular}{|c|c|c|c|c|c|c|}
\hline Produto & Quantidade & $\begin{array}{c}\text { Custo } \\
\text { Unitário } \\
(\mathbf{R} \$)\end{array}$ & $\begin{array}{l}\text { Custo } \\
\text { Total } \\
(\mathbf{R} \$) \\
\end{array}$ & $\begin{array}{c}\text { Percentual } \\
(\%)\end{array}$ & $\begin{array}{c}\text { Percentual } \\
\text { Acumulado } \\
(\%) \\
\end{array}$ & $\begin{array}{c}\text { Classificação } \\
\text { ABC }\end{array}$ \\
\hline Tequila & 6 & 50,00 & 300,00 & 0,86 & 80,97 & $\mathrm{~B}$ \\
\hline Xarope de chocolate & 7 & 39,90 & 279,30 & 0,80 & 81,77 & $\mathrm{~B}$ \\
\hline Xarope de curaçau blue & 7 & 39,90 & 279,30 & 0,80 & 82,58 & $\mathrm{~B}$ \\
\hline Xarope de menta & 7 & 39,90 & 279,30 & 0,80 & 83,38 & $\mathrm{~B}$ \\
\hline Xarope de grenadine & 7 & 39,90 & 279,30 & 0,80 & 84,19 & $\mathrm{~B}$ \\
\hline Xarope de pêssego & 7 & 39,90 & 279,30 & 0,80 & 84,99 & $\mathrm{~B}$ \\
\hline Xarope de coco & 7 & 39,90 & 279,30 & 0,80 & 85,79 & $\mathrm{~B}$ \\
\hline Xarope de morango & 7 & 39,90 & 279,30 & 0,80 & 86,60 & $\mathrm{~B}$ \\
\hline Xarope de cassis & 7 & 39,90 & 279,30 & 0,80 & 87,40 & $\mathrm{~B}$ \\
\hline Xarope de maçã verde & 7 & 39,90 & 279,30 & 0,80 & 88,20 & $\mathrm{~B}$ \\
\hline Suco de abacaxi & 48 & 5,50 & 264,00 & 0,76 & 88,96 & $\mathrm{~B}$ \\
\hline Conhaque & 7 & 36,40 & 254,80 & 0,73 & 89,70 & $\mathrm{~B}$ \\
\hline Cuba de frutas pequena & 3 & 80,00 & 240,00 & 0,69 & 90,39 & $\mathrm{~B}$ \\
\hline Cachaça & 7 & 30,00 & 210,00 & 0,60 & 90,99 & $\mathrm{~B}$ \\
\hline Saque & 7 & 29,90 & 209,30 & 0,60 & 91,60 & $\mathrm{~B}$ \\
\hline Org. de bar & 7 & 28,30 & 198,10 & 0,57 & 92,17 & $\mathrm{~B}$ \\
\hline Suco de laranja & 36 & 5,50 & 198,00 & 0,57 & 92,74 & B \\
\hline Absinto & 4 & 45,00 & 180,00 & 0,52 & 93,25 & $\mathrm{~B}$ \\
\hline Suco frutas vermelhas & 36 & 5,00 & 180,00 & 0,52 & 93,77 & $\mathrm{~B}$ \\
\hline Pistola & 3 & 59,90 & 179,70 & 0,52 & 94,29 & $\mathrm{~B}$ \\
\hline Sprite & 36 & 4,74 & 170,64 & 0,49 & 94,78 & $\mathrm{~B}$ \\
\hline
\end{tabular}

Fonte: Elaborado pelos autores.

Os itens classificados como B na curva são considerados produtos intermediários em termos de investimento para a empresa, mas requerem certa atenção, pois também possuem alto custo, resultando em um dispêndio de capital de $\mathrm{R} \$ 5.098,24$. Pode-se notar 
que grande maioria dos produtos são xaropes, sucos e demais complementos, estes itens somam $32,81 \%$ dos produtos da empresa.

Na Tabela 03, apresentam-se os itens classificados como C:

Tabela 03 - Itens da classe C da empresa

\begin{tabular}{|c|c|c|c|c|c|c|}
\hline Produto & Quantidade & $\begin{array}{c}\text { Custo } \\
\text { Unitário } \\
(\mathbf{R} \$) \\
\end{array}$ & $\begin{array}{c}\text { Custo } \\
\text { Total } \\
(\mathbf{R} \$)\end{array}$ & $\begin{array}{c}\text { Percentual } \\
(\%)\end{array}$ & $\begin{array}{c}\text { Percentual } \\
\text { Acumulado } \\
(\%)\end{array}$ & $\begin{array}{c}\text { Classificação } \\
\text { ABC }\end{array}$ \\
\hline Storen pour & 6 & 21,90 & 131,40 & 0,38 & 95,16 & $\mathrm{C}$ \\
\hline Tabua de corte & 7 & 18,70 & 130,90 & 0,38 & 95,54 & $\mathrm{C}$ \\
\hline Extensão & 7 & 17,90 & 125,30 & 0,36 & 95,90 & $\mathrm{C}$ \\
\hline Pegador de gelo & 14 & 8,90 & 124,60 & 0,36 & 96,25 & $\mathrm{C}$ \\
\hline Bailarina & 7 & 15,00 & 105,00 & 0,30 & 96,56 & $\mathrm{C}$ \\
\hline Dosador & 7 & 14,90 & 104,30 & 0,30 & 96,86 & $\mathrm{C}$ \\
\hline Balde de gelo & 9 & 10,99 & 98,91 & 0,28 & 97,14 & $\mathrm{C}$ \\
\hline Leite de coco & 24 & 3,49 & 83,76 & 0,24 & 97,38 & $\mathrm{C}$ \\
\hline Leite condensado & 24 & 3,39 & 81,36 & 0,23 & 97,62 & $\mathrm{C}$ \\
\hline Creme de leite & 24 & 2,79 & 66,96 & 0,19 & 97,81 & $\mathrm{C}$ \\
\hline Biqueira & 20 & 3,00 & 60,00 & 0,17 & 97,98 & $\mathrm{C}$ \\
\hline Canhão de led & 1 & 59,90 & 59,90 & 0,17 & 98,15 & $\mathrm{C}$ \\
\hline Liquidificador & 1 & 49,90 & 49,90 & 0,14 & 98,30 & $\mathrm{C}$ \\
\hline Licor de cacau & 1 & 39,90 & 39,90 & 0,11 & 98,41 & $\mathrm{C}$ \\
\hline Licor de cassis & 1 & 39,90 & 39,90 & 0,11 & 98,53 & $\mathrm{C}$ \\
\hline Licor de chocolate & 1 & 39,90 & 39,90 & 0,11 & 98,64 & $\mathrm{C}$ \\
\hline Licor de cocoblanc & 1 & 39,90 & 39,90 & 0,11 & 98,76 & $\mathrm{C}$ \\
\hline Pá de gelo & 2 & 7,80 & 15,60 & 0,04 & 99,97 & $\mathrm{C}$ \\
\hline Colher & 8 & 1,28 & 10,24 & 0,03 & 100,00 & $\mathrm{C}$ \\
\hline
\end{tabular}

Fonte: Elaborado pelos autores.

Conforme apresentado na Tabela 03 , os itens da classe $\mathrm{C}$ representam uma parcela considerável dos itens em estoque da empresa, porém possuem um menor valor de custo total. Estes são itens que possuem demanda em quantidade razoável, mas que, em função do seu baixo valor unitário e total, foram classificados na classe $\mathrm{C}$. O valor total do investimento nesta classe totalizada $\mathrm{R} \$ 1.813,49$, representando $50 \%$ do total de itens considerado na análise $\mathrm{ABC}$. Os resultados obtidos por meio da classificação da classe $\mathrm{C}$ na Fest Entretenimentos corroboram os achados de Vago et al. (2013), os quais afirmam que o espaço físico no almoxarifado é maior, em função da classe $\mathrm{C}$ apresentar um percentual maior de itens, tornando necessária uma revisão dos estoques.

Por meio da classificação foi possível elaborar a curva $\mathrm{ABC}$, apresentada na Figura 02. 


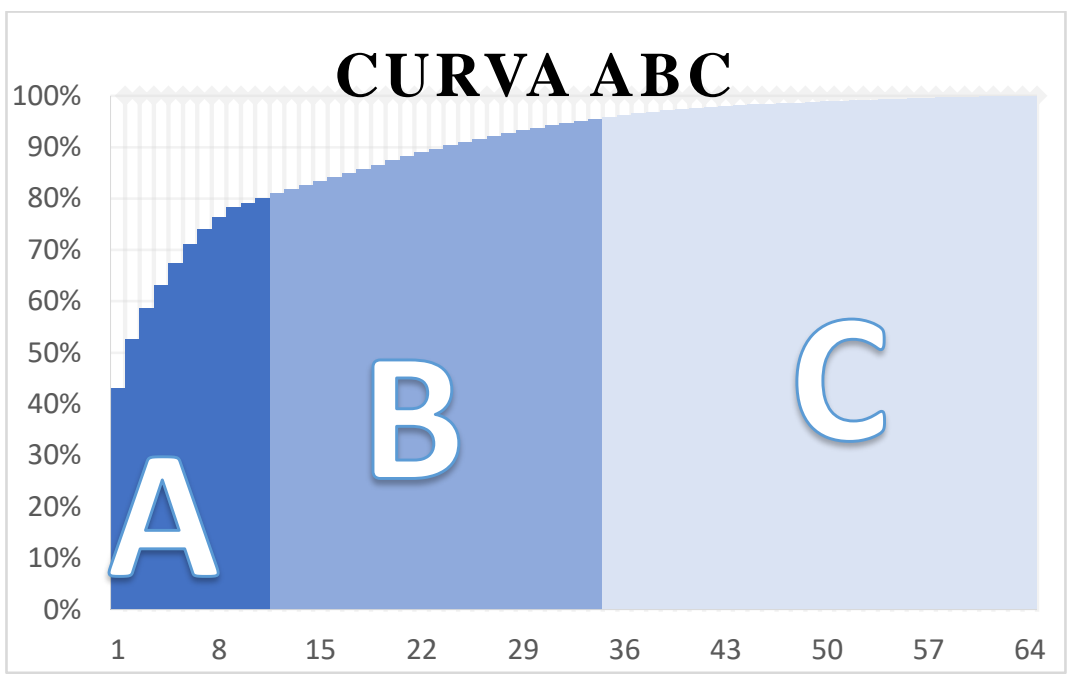

Figura 02 - Curva $\mathrm{ABC}$ da Fest Entretenimentos

Fonte: Elaborado pelo autor

Conforme exposto, os valores que compõem a base do gráfico (eixo $\mathrm{x}$ ) demonstram o número total de itens. Na vertical (eixo y) está a porcentagem que os itens ocupam, ou seja, a classe A da curva ABC é formada por onze itens que representam $17,19 \%$ do total de produtos vendidos na empresa. Na classe B, o levantamento encontrado foi de vinte e um produtos, totalizando um percentual de $32,81 \%$ do total em estudo. Para os itens da classe $\mathrm{C}$, verifica-se que foram encontrados trinta e dois itens, totalizando um percentual de $50 \%$.

Logo, é possível verificar que, por meio da análise da curva $\mathrm{ABC}$, os itens foram classificados de maior a menor importância para o estoque, permitindo à empresa o conhecimento dos itens que merecem maior atenção e investimento em relação aos demais para que a prestação de serviços da empresa ocorra de maneira contínua, sem haver ruptura por falta de materiais. Dessa forma, mediante a definição da curva ABC, o controle de estoque da empresa aumenta de maneira efetiva a otimização do capital investido, o que pode trazer à empresa diferencial competitivo, pois é possível reduzir as perdas, controlar a demanda do material e saber quando e quais materiais são necessários comprar sem que haja desperdícios. 


\section{CONSIDERAÇÕES FINAIS}

As empresas estão cada vez mais preocupadas com a análise cuidadosa de seus estoques, devido a dois principais motivos: a quantidade significativa de capital investido nos estoques, o qual, se otimizado, pode vir a se tornar um diferencial competitivo perante seus concorrentes e; o abastecimento adequado dos materiais necessários de modo a evitar interrupções no processo produtivo e de prestação de serviços. Sendo assim, o presente estudo analisou o estoque da empresa Fest Entretenimentos por meio do cadastramento dos produtos utilizados para a prestação de serviços, de maneira a verificar seu consumo por meio da curva $\mathrm{ABC}$.

Para tanto, inicialmente foi realizado o levantamento de todos os dados necessários referentes aos cem produtos mais consumidos no período estudado, de fevereiro a junho de 2018, para então tornar exequível a proposta da curva ABC, sendo necessário evidenciar os custos unitários dos produtos, custos totais e as quantidades vendidas.

Dessa forma, foi possível mensurar os produtos que possuem maior impacto em relação aos valores monetários, que somam um montante de $\mathrm{R} \$ 34.743,29$, onde estão os itens da classe A, que representam aproximadamente $80 \%$ do valor investido em estoques. Estes itens são tratados como produtos de alto valor monetário para a empresa, assim, por meio deste estudo foi possível verificar as especificidades que envolvem alto investimento de recursos nesta classe. Os produtos de classificação B são compostos por vinte e cinco itens de importância intermediaria na organização, totalizando aproximadamente $15 \%$ da demanda em valor monetário. Consequentemente, os itens da classe $\mathrm{C}$, por possuírem um baixo valor agregado, representam grande quantidade de produtos, o que corresponde a apenas aproximadamente $5 \%$ do valor de demanda monetária.

Conclui-se, por meio da realização deste estudo, que a eximia gestão do estoque possui grande relevância para a empresa, pois se torna uma ferramenta competitiva e possibilita a minimização de perdas de materiais. Sendo assim, os objetivos deste estudo foram alcançados, refletindo em uma estimativa de melhorias significativas, sendo possível colocar em prática tudo que foi passado em sala de aula pelos professores e revisados através de bibliografias. 
Para estudos futuros, recomenda-se analisar a viabilidade da compra de um sistema de gerenciamento de estoque, podendo aumentar os controles, reduzindo os custos e desperdícios, aumentando a capacidade produtiva do estoque. Dessa forma, sugere-se que seja desenvolvido um sistema de etiquetas, a fim de facilitar na hora do cadastramento, bem como nos levantamentos dos produtos em estoques periódicos.

\section{REFERÊNCIAS}

ARAÚJO, G. C.; SILVA, J. P. Z. da; SOUZA, L. R.; LOUREIRO, M. B.; FERONI, R. de C. Brazilian Journal of Production Engineering, v. 4, n. 2, p. 48-64, 2016.

BALlOU, R. H. Gerenciamento da Cadeia de Suprimentos Logística Empresarial. Porto Alegre: Bookman, 2006.

BALlOU, R. H. Logística Empresarial: Transportes, Administração de Materiais e Distribuição Física. São Paulo: Atlas, 1993.

BEZERRA, T. C.; ARAÚJO, M. C. B. de. Aplicação da Curva ABC para Planejamento de Compras: um Estudo de Caso em uma Empresa de Autopeças na Cidade de Currais Novos/RN In: VI Simpósio de Engenharia de Produção, 2018, Salvador. VI Simpósio de Engenharia de Produção - SIMEP, 2018. v. 6.

CORREA, Henrique L; CORREA, Carlos A. Administração de Produção e Operações: Manufatura e Serviços. 2. ed. São Paulo: Atlas, 2006.

DIAS, M. A. P. Administração de Materiais: Princípios, Conceitos e Gestão. 6 ed. São Paulo: Atlas, 2012.

DIAS, M. A. P. Administração de Materiais: uma Abordagem Logística. 5. ed. São Paulo: Atlas, 2010.

FARIA, A. C. de; COSTA, M. de F. G. Gestão de Custos Logísticos. São Paulo: Atlas, 2005.

GIANESI, I. G. N.; BIAZZI, J. L. Gestão Estratégica de Estoques. Revista de Administração, São Paulo, v. 6, n. 3, p. 290-304, jul./ago./set. 2011.

GRESSLER, Lori Alice. Introdução à Pesquisa: Projetos e Relatórios. 2 ed. São Paulo: Loyola, 2004.

HAIR Jr., J.F.; BLACK, W.C.; BABIN, B.J.; ANDERSON, R.E. \& TATHAM, R.L. Análise Multivariada de Dados. 6.ed. Porto Alegre, Bookman, 2009.

REMIPE- Revista de Micro e Pequenas Empresas e Empreendedorismo da Fatec Osasco V. 7 N $^{\circ} 2$ set.2021 a fev. 2022. 
KNAPP, Eduardo. Folha de São Paulo, São Paulo, 14 jun. de 2016. Disponível em: https://www1.folha.uol.com.br/mercado/2016/06/1781343-entretenimento-e-midia-vaocrescer-mais-no-brasil-que-no-mundo-diz-pwc.shtml. Acesso em: 18 mar. 2018.

LOURENÇO, K. G.; CASTILHO, V. Classificação ABC dos Materiais: uma Ferramenta Gerencial de Custos em Enfermagem. Revista Brasileira de Enfermagem - REBEn. v. 59 , n. 1, p. 52-55, 2006.

MARTINS, P. G.; LAUGENI, F. P. Administração da Produção. 2. ed. São Paulo: Saraiva, 2006.

NACK, B. C. G.; BONFADINI, G. J. Gestão de Compras na Cadeia de Suprimentos Analisando os Fornecedores de Itens da Classe C (curva ABC). Revista Estudo \& Debate, v. 20, n. 2, p. 147-158, 2013.

OLIVEIRA, M. A. M.; SILVA, M. M. da; ANDRADE, W.A.; FORMIGONI, A. Gestão de Estoques em uma Metalúrgica do Setor de Autopeças. Revista de Micro e Pequenas Empresas e Empreendedorismo da Fatec Osasco - REMIPE, v. 1, n. 2, jul./dez. 2015.

POZO, Hamilton. Administração de Recursos Materiais e Patrimoniais: uma Abordagem Logística. 4. ed. São Paulo: Atlas, 2010.

RODRIGUES, D. A.; LACERDA SOBRINHO, G. P.; REZENDE, J. B. M. de; SILVA, M. V. da; SILVA, V. G. M. Gestão de Estoque: Estudo de Caso Aplicado em Indústrias Moveleiras de Carmo do Cajuru/MG. Revista Research, Society and Development, v. 7, n. 5, p. 01-15, 2018

SANTOS, J. A. A. dos; GRANDER, G. Análise e Simulação do Sistema de Estocagem de uma Indústria Moveleira: um Estudo de Caso. Fasci-Tech: Periódico Eletrônico da FATEC, v. 1, n. 6, Mar./Set. 2012.

SILVA, V. G. M.; GOMES, M. G.; BRAGA, C. C.; RUFINO, V. E. Controle de Estoque: um Estudo Sobre a Eficiência da Gestão de Estoque numa Distribuidora Atacadista de Divinópolis, MG. Revista Research, Society and Development, v. 7, n. 5, p. 01-16, 2018.

SLACK, N.; CHAMBERS, S.; JOHNSTON, Robert. Administração da Produção. 2. ed. São Paulo: Atlas, 2007.

RONCHI, L. M. Os Reflexos da Análise da Curva ABC na Gestão de Estoques de uma Empresa Comercial de Materiais de Construção. 2014. 58p. Monografia (Graduação em Ciências Contábeis) - Universidade do Extremo Sul Catarinense, Criciúma, 2014.

VAGO, F. R. M.; SOUSA, C. V.; MELO, J. M. do C.; LARA, J. E.; FAGUNDES, A. F. A.; SAMPAIO, D. de O. A Importância do Gerenciamento de Estoque por Meio da Ferramenta ABC. Revista Sociais e Humanas, v. 26, n. 03, p. 638-655, set./dez. 2013.

REMIPE- Revista de Micro e Pequenas Empresas e Empreendedorismo da Fatec Osasco V. 7 N² set.2021 a fev. 2022. 
WANKE, PETER. Gestão de Estoques na Cadeia de Suprimento: Decisões e Modelos Quantitativos. 2. ed. São Paulo: Atlas, 2006.

YIN, Robert. K. Estudo de Caso: Planejamento e Métodos. 3. ed. Porto Alegre: Bookman, 2005. 